\title{
The social mission of Australian medical schools in a time of expansion
}

\author{
John S. G. Biggs ${ }^{1,3}$ MA, MD, FRCOG, FRANZCOG, Visiting Fellow \\ Robert W. Wells ${ }^{1,2}$ BA, Director \\ ${ }^{1}$ Australian Primary Health Care Research Institute, Australian National University, Level 1, Ian Potter House Corner \\ of Gordon and Marcus Clarke Streets, Acton, ACT 2601, Australia. Email: robert.wells@anu.edu.au \\ ${ }^{2}$ Menzies Centre for Health Policy, Australian National University, Level 1, Ian Potter House, \\ Corner of Gordon and Marcus Clarke Streets, Acton, ACT 2601, Australia. \\ ${ }^{3}$ Corresponding author. Email: jsgb@homemail.com.au
}

\begin{abstract}
The social mission, or accepted social responsibility of Australian medical schools, was assessed at a time of rapid expansion and resulting pressure on staff and facilities. Nine new schools have been established in $2005-10$ and there has been particular concern about adequacy of clinical training places. Discussions with most of the deans revealed their strong social commitments. We consider two of these in depth - raising the status and thus the involvement of students in general and especially rural practice; and increasing the numbers of Indigenous students and the knowledge of Indigenous health and culture among all students. We examine a system by which medical schools in the USA have been ranked for social mission achievements and suggest this approach might be used in Australia to measure the response of medical schools to Government initiatives and policies.
\end{abstract}

What is known about this topic? The rapid expansion of medical schools and student numbers has given rise to much concern. Encouragement of training for general practice is well described. Many medical schools have worked to increase intake of Indigenous students. Data on medical graduates are being gathered.

What does this paper add? The social mission and responsibility of medical schools is new to Australia; information was obtained by interview of medical deans and review of the international literature. Matters of special note are rural healthcare, developments in general practice and expansion of support for Indigenous students. Recent studies of graduate output in the USA are considered.

What are the implications for practitioners? Expansion of medical student numbers has brought increased demand for general practitioner involvement in training of students and graduates, which affects practice resources. The need for workforce planning to match training paths and places with future national needs means medical schools have new responsibilities for career guidance of students.

Received 13 October 2010, accepted 31 January 2011, published online 30 September 2011

\section{Introduction}

Medical schools in Australia are under many pressures, from governments to expand, from universities faced with inadequate finance, and from students seeking places. The rapid expansion of schools in the last 5 years has resulted in shortages of staff and clinical placements for students, and insufficient intern places for graduates. Despite these pressures, medical schools have a responsibility to meet their communities' health needs and those of the nation with what is termed their Social Mission. We describe the expansion in medical schools in Australia, outline the social mission as seen by the deans of medical schools, and concentrate on two: the improvement of rural health, and that of Indigenous Peoples (Aborigines and Torres Strait Islanders).

\section{Methodology}

Face-to-face or telephone interviews were held with 10 of the medical deans in Australia. The deans were selected to provide a cross section of schools by size, new or established and geographical location.

\section{A time of expansion}

The number of medical schools in Australia increased sporadically for 150 years, but dramatically in the last 5 years; nine new schools have opened since 2010.

Admissions showed little increase in 1980-2000, when many felt Australia was oversupplied with doctors. ${ }^{1}$ Admissions were 
kept at $\sim 1200$ per year during this time, ${ }^{2}$ but by 2004 there was evidence of a shortage despite continuing immigration of qualified doctors from overseas. Student intakes rose quickly as new schools have opened, from 1660 in 2000 to 3442 in 2009, an expansion of $107 \%$. $^{3}$

International students filled $20 \%$ of available places in recent years but at a decreasing proportion since 2005 . Fees paid for these places are up to AU\$60000 per year and universities have seen the students as an essential resource at a time of funding shortfall.

The expansion of medical schools was rapid and problems were foreseen. The availability of clinical placements would prove a major problem and the Medical Deans of Australia and New Zealand (The Medical Deans) listed options in a report of $2008 .^{4}$ These included general practice, the private sector, Indigenous health settings, rural and community health centres, the newly emerging Super Clinics, aged care, and ambulance services. As described below, medical students are gaining clinical experience in rural clinical schools, learning in Aboriginal health services, and gaining instruction in aged care facilities, but there remains a shortage of sources of clinical experience. As new schools' move to their first graduating class, the demand for intern places is likely to exceed supply. Graduate numbers will increase by $181 \%$ from 2000 to 2014 and the spectre of unemployed graduates has been raised. ${ }^{5}$

The problem already exists for international medical students, who are generally ineligible for intern places. The seriousness of the problem is seen in a call by the Medical Deans on 9 March $2010,^{5}$ for ' . . a guarantee of training places for all medical graduates, whether they be Commonwealth-funded, fee-paying domestic or international students ... . Expressing concern about medical school expansion, Medical Deans issued wider warnings on 13 April 2010 calling for a halt in expansion for at least 2 years. ${ }^{6}$ On 19 August they detailed the problems facing medical education, ${ }^{7}$ saying 'there are not the resources in place to ensure that all current medical students will have the vocational training to become fully qualified practicing doctors'. Shortages were cited in clinical training places, internships and vocational training places for graduating students.

In summary, the expansion in medical education in Australia in the last 5 years will increase the number of doctors available for health services, but has put great pressure on medical schools. New schools are becoming established and some older ones have expanded and formed new clinical schools at a distance. Problems of insufficient clinical places are already causing tensions and shortages of intern placements lie ahead.

\section{Social mission and responsibility: the schools' perspectives}

In laying the ground for social missions we spoke to the deans of most of the schools, asking them to tell us about their social mission. Six principal domains were found:

(i) Responsibility to the community. An encouraging start came from the dean who responded: 'our mission is to ensure a quality health service for the State; that's what we were established for'. Several deans expressed a similar mission of responsibility to the people. Others said: 'we see our mission as engaging with society and the health professions', and 'we want to ensure clinical preparedness in our graduates and their confidence in communicating with patients, health personnel and colleagues'.

(ii) The influence of establishment. The deans of schools closely associated with research institutions spoke of the premium they placed on preparing students to be leaders in research and top-flight clinicians. The importance of maintaining leadership in these areas was acknowledged.

(iii) The influence of locality. The vision statement of the northern-most medical school, James Cook University in Townsville, expresses a principal mission that comes from identity with its place: ' . . in particular, programs will be responsive to the health needs of the communities of Northern Australia and the School will be a leader in the focus areas of rural and remote health, Indigenous health and tropical medicine for Australia and the Asia-Pacific region'. ${ }^{8}$ Schools in regional areas expressed a bias towards rural health.

(iv) General practice. All schools described their involvement in raising an awareness and interest in general practice. All have student attachment to general practices during their course.

(v) Rural responsibility. Deans gave priority to students gaining understanding and involvement in rural healthcare. Several spoke of the development of rural clinical schools where students gained experience in regional hospitals and with area general practitioners, and of the success of rural learning. One dean told how the school's rural clinical placements had revived health services in coastal townships and overcome threatened closure of local hospitals.

(vi) Awareness of Indigenous health needs. Medical schools have provided secure places for Indigenous students for more than 25 years and deans told of efforts to encourage their successful filling. They told of community awareness programs to encourage potential students and an eagerness to accommodate them and offer support.

In essence, Australian medical schools have a range of social missions; service to a school's State and community is prominent; research promotion is important in longer-established schools. There is a common commitment to general practice, especially to rural experience and learning, and support for increasing numbers of Indigenous students. We consider these subjects in depth below.

\section{Social mission: to improve rural health}

Standards of healthcare beyond the major cities of Australia are receiving increasing attention and medical schools, prompted by governments, are conscious of their responsibilities in this field. Rural is put in the context of remoteness, defined by distance from a major city in four categories - inner regional, outer regional, remote and very remote and applied to everything outside the major cities. $^{9}$

The National Rural Health Alliance wrote in 2010 of the inequity in rural health provision. ${ }^{10}$ It said people in rural and remote areas lost 4 years of life expectancy when compared to those in major cities. It showed that in 2006-07 the number of doctors per 100000 people decreased progressively from 324 in major cities to 148 in outer regional and 70 in very remote areas. Numbers of dental, nursing and pharmacy workers decreased in 
the same way. Poorer health outcomes for rural communities in Australia are well-documented, with lower life expectancy and higher prevalence of chronic diseases and of risk factors such as tobacco and alcohol consumption. ${ }^{11}$

The rural pipeline, by which students with a rural upbringing train in rural areas and are more likely to settle and work in a rural area, has been documented. ${ }^{12}$ Australian Government scholarships for rural medical students endorse this finding. The Rural Australia Medical Undergraduate Scheme (RAMUS) scholarships provide AU\$10 000 per year, for students who have lived in a rural area for at least 5 years; 100 new scholarships are offered each year. ${ }^{13}$ The Medical Rural Bonded Scholarship Scheme provides AU\$23 686 per year throughout the course and holders are bound for 6 years practice in rural or remote areas after completing vocational qualifications; there are 100 new scholarships per year. ${ }^{14}$ The Bonded Medical Places (BMP) scheme requires students to serve after graduation in rural or other areas of need, for a time equal to the length of the medical course ${ }^{15}$; there are 600 places each year with 2279 holders in 2009.

Medical schools have introduced training of students in rural areas following encouragement by other Government initiatives. In 1997 the Australian Government funded the establishment of University Departments of Rural Health, and in 2000 launched the Rural Clinical Schools program with the aim of providing extended clinical training in regional areas that conformed to the curriculum of the parent medical school. ${ }^{16}$ The rural schools were expected to strengthen the local health workforce and raise the standard of local healthcare while encouraging students and clinicians to settle and work in rural areas. Fourteen rural clinical schools have been established and their prospects have been enlarged by a Government decision in 2006 that $25 \%$ of all Commonwealth-funded students spend at least 1 year of clinical training in rural communities.

Students at the schools attend the regional hospital and other health services and have regular attendance at one or more general practices. There are sessions of instruction at the school, often by video link with the main campus. A program at Flinders University rural clinical school is illustrative, telling how students learn clinical subjects as in the city, but in an integrated way, seeing patients in general practices and following them through the hospital system. They sit the same exams as their [city]-based colleagues. $^{16}$

The potential effect of rural experience on future medical careers has been well studied in Australia, ${ }^{12,17,18}$ and shortterm, ${ }^{19-21}$ as well as longer term positive outcomes are described. ${ }^{22,23}$ Flinders Medical School tells how students in a 4-year graduate entry program who undertook year 3 clinical studies in a rural remote setting performed significantly better in end of year exams than those who remained in Adelaide. ${ }^{24}$ The social mission of expanding rural healthcare is thus being pursued energetically in Australia, prompted and supported by Government, and providing new resources for rural regions and readily accepted training for medical students.

\section{Social mission: to improve the healthcare of Indigenous peoples}

The health problems of Indigenous peoples in Australia are widely known and a 2008 report showed deficiencies in their welfare which compounded deficiencies in their health. ${ }^{25}$ In June 2006 there were 517200 Indigenous people, 2.5\% of the Australian population. They were younger than the non-Indigenous (NI) population with a median age of 21 years, compared with 36 years. Most lived in regional areas (43\%), with 32\% in cities and $25 \%$ in remote areas. The unemployment rate for those aged 15-64 years was $16 \%$, well above the NI rate of 5\%. The median household income was AU\$362 per week, just above half the NI figure of AU\$642. One in every two Indigenous households was receiving some form of government housing assistance.

But what of health? The life expectancy at birth was 67.2 years for Indigenous males and 72.9 years for females, deficits of $\sim 10$ years from the NI figures. Causes of serious long-term health problems for Indigenous people were cardiovascular disease, diabetes (both types 1 and 2), respiratory diseases, musculoskeletal conditions, kidney disease, and eye and ear disorders. Half of all Indigenous people over the age of 15 smoked. Indigenous people were admitted to hospital for renal dialysis at 14 times the rate of NI; general practitioners saw Indigenous people with diabetes at three times the rate of NI. Indigenous adults were twice as likely as NI to report high or very high levels of psychological distress. There have been energetic steps to overcome these problems. Meanwhile there is a growing role of medical schools in addressing health needs of Indigenous Peoples; first by encouraging entry of Indigenous students into the medical course, and second, by building instruction in Indigenous life and health into the medical curriculum.

\section{Indigenous medical students}

Efforts to bring Indigenous students into medical schools began in the 1980 s with spreading of information to high schools, reservation of places, and identification of tutors and mentors. The University of Newcastle (NSW) medical school took a lead with an emphasis on encouragement and a support network. By 2007, 51 Indigenous doctors had graduated, more than half of the Australian total. ${ }^{26}$ A Western Australian graduate of 1983, said to be the first Aboriginal doctor in Australia, is now Professor of Psychiatry. ${ }^{27}$ A Centre for Aboriginal Health was started there in 1996 to improve recruitment and retention of Indigenous students. A University of Queensland graduate of 1990 has told of his work at the Inala Indigenous Health Service in Brisbane; from 12 patients on his arrival in 1994 there are now more than 3000, and the Service has become a centre of excellence for Indigenous primary care. $^{27}$

The programs are seen as providing Indigenous doctors, many of whom wish to work in Indigenous health. The Australian Indigenous Doctors' Association (AIDA) has given life stories of graduates who demonstrate this ambition. ${ }^{27} \mathrm{~A}$ senior medical dean said there were now 150 Indigenous students in training; he believes there is a need for 450 (Prof J. Angus, pers. comm., 2010).

\section{The Indigenous medical curriculum}

A curriculum framework for Indigenous Health was developed by the Committee of Deans in 2004. ${ }^{28}$ A collaboration agreement was reached by the Deans and AIDA. ${ }^{29}$ The curriculum was adopted by the Australian Medical Council (AMC), and now forms part of the standards required to be met by Schools. ${ }^{30}$ 
Accordingly, students learn about Aboriginal and Torres Strait history, culture and medicines, population health, health service delivery, clinical presentations common in Indigenous people and communication skills.

\section{Discussion}

The rapid rise in medical school and student numbers in the last 5 years has raised difficulties in staffing, infrastructure and clinical placements in hospitals but also in general practice. ${ }^{31}$ These have been managed, and in part overcome, but problems remain.

A looming rise in graduates and the resultant demand for intern places has been called a crisis and calls made for new infrastructure, new intern settings and more supervising staff. ${ }^{32}$ The Medical Deans have issued a strong warning of the risks of further expansion, saying there must be no further increase in student numbers for at least 2 years lest training standards are compromised. They expressed concern that there are insufficient quality training places available and believed a halt in rising numbers was essential until internship problems had been resolved. ${ }^{6}$ The shortage of training opportunities at intern level will quickly become a shortage at all postgraduate training levels. Planning for allocation of what will become scarce career paths should be a high priority for the national workforce training body, Health Workforce Australia (see http://www.hwa.gov.au).

A Government review of undergraduate medical education in $2008^{33}$ drew attention to the lack of finance in universities and clinical settings, the pressure of increasing numbers of students in medical schools, the smaller number of educators, fewer clinical places and tensions between clinical teaching and service. It told of shortages of healthcare personnel in general practice and rural and remote areas and of the rapid changes in doctors' practice and medical curricula.

In September 2010, a joint statement ${ }^{34}$ from the Australian Medical Association, the Australian Medical Students' Association, the Medical Deans and the Confederation of Postgraduate Medical Education Councils called for Government to increase funds for support of medical training and action on medical workforce planning - to establish a planning framework that produces the number and type of medical practitioners that the community needs. There is clearly dissatisfaction among the medical profession with government planning of workforce, or perhaps it is impatience at the time taken for effective planning and execution. A plethora of national committees has made recommendations and collected data (the Medical Training Review Panel is praised in the joint statement for its data and its regular reports). One wonders if notice is being taken of the advice offered.

The principal social missions addressed in this paper are for rural healthcare, by inference the training of general practitioners (GPs), and increasing the recruitment to medicine of Indigenous students. Although the need for more GPs was made clear in a 2005 report $^{35}$ and the Government has responded by annually increasing the number of new GP trainees, there is little information on the longer-term outcome of the training. The shortage of primary care doctors in rural and remote areas is known but there is no knowledge of the influence of each medical school in helping to overcome the deficits. Similarly, although schools such as Newcastle, Western Australia and James Cook have demonstrated their commitment, little is known of the longer term results of encouragement of Indigenous students into Medicine. A recent report from Mullan et al. in the United States shows what can be done in finding such information. ${ }^{36}$

All 141 medical and osteopathic schools in the USA, which produce registered practitioners, were assessed for the percentage of their graduates who practice primary care, the percentage who work in areas of health profession shortage, and the percentage of their graduates from underrepresented minorities - African Americans, Hispanics and Native Americans. The three measures were combined to form a 'Composite Social Mission Score'; data on 60000 graduates from 1999-2001 were used to rank the schools, the years from graduation to analysis allowing most graduates to be settled in practice. The results showed that research-strong schools scored poorly; there was an inverse relationship between a school's score and its production of primary care physicians. The study points to the schools to which added support might be given in attempting to reach social goals of equity in primary care provision and opportunity for medical training.

In Australia, Government encouragement has been evident in all three areas: primary care, rural and remote practice, and Indigenous doctors. The response of each medical school would be useful information in planning future funding. The Medical Deans have gathered data on all Australian and New Zealand medical graduates since 2005 and plan to seek information 3 and 5 years after graduation. ${ }^{37}$ It is to be hoped they will have the opportunity to provide, if not a social mission score for each medical school, at least information on the outcomes in the three areas for each school.

An Australian Government audit of the health workforce in 2008 found that '.. rural and remote Australia had experienced medical workforce shortages for a considerable time, especially in general practice services and specialties such as obstetrics and gynaecology'. ${ }^{38}$ Details in the audit show that full-time general practitioner numbers in rural and remote areas have been maintained in recent years, in large part by the requirement that overseas trained doctors spend 10 years in rural or other areas of need; in 2008 they made up $41 \%$ of practitioners in rural areas. It might be hoped that the efforts of medical schools, supported by the Government, will bring Australian graduates to rural practice, against the time when the 10 -year moratorium is lifted.

\section{Conclusion}

The social missions of Australian medical schools have been identified as providing quality staff for healthcare, increasing the number of general practitioners and rural doctors and increasing access to medical training for Indigenous Peoples. The very recent and rapid expansion of medical schools and student numbers is presenting problems and a shortage of intern places appears imminent. Greater attention needs to be given to future planning of the medical workforce. A method of ranking medical schools in the USA by their social mission achievements suggests action that might be taken in Australia. Further research will be needed to assess the effect of various government priorities and approaches aiming to increase Indigenous doctors, doctors choosing general practice as a career and those practicing in rural and remote areas 
and this work should inform future policies both for government and medical schools.

The development of medical education in Australia in the last 20 years has been closely linked to health and social policy, through university initiatives and specific Australian Government programs. The rapid expansion has caused problems but the growing student experience of general practice and rural health and the growth of Indigenous student involvement in medical courses and practices are evidence that the medical schools are striving sensibly and effectively to fulfil their social missions and meet the expectations of society.

\section{Competing interests}

The authors declare that no conflicts of interest exist.

\section{References}

1 National Health Workforce Taskforce. Self Sufficiency and International Medical Graduates - Australia. Canberra, ACT: Council of Australian Governments; 2008. Available at http://www.nhwt.gov.au/documents/ NHWT/ [verified 5 September 2011].

2 Report on the Audit of Health Workforce in Rural and Regional Australia. Canberra, ACT: Department of Health and Ageing; 2008. p. 31.

3 Medical Training Review Panel, April 2010. Canberra, ACT: Department of Health and Ageing; 2010. p. 6.

4 National Clinical Training Review: Report to the Medical Training Review Panel, March 2008. Sydney: Medical Deans of Australia and New Zealand; 2008.

5 Medical students may never qualify, warn Deans. Media release, 9 March 2010. Medical Deans of Australia and New Zealand; 2010. Available at http://www.medicaldeans.org.au/medical-students-may-never-qualifywarn-deans.html [verified 5 September 2011].

6 Keep medical student numbers on hold. Media release, 13 April 2010. Sydney: Medical Deans of Australia and New Zealand;2010. Available at http://www.medicaldeans.org.au/hello-world.html [verified 5 September 2011].

7 No new schools before 2014, say Deans. Media release, 19 August 2010. Sydney: Medical Deans of Australia and New Zealand; 2010. Available at http://www.medicaldeans.org.au/no-new-schools-before-2014-saydeans.html [verified 5 September 2011].

8 Accreditation of The School of Medicine, Health and Molecular Sciences James Cook University. November 2007. Kingston ACT: Australian Medical Council; 2007.

9 Measuring Remoteness: Accessibility/Remoteness Index of Australia (ARIA) Revised Edition, 29 October 2001. Commonwealth of Australia, Canberra.

10 Measuring the metropolitan-rural inequity, 9 September 2010. Deakin West, ACT: National Rural Health Alliance; 2010.

11 A Snapshot of Men's Health in Regional and Remote Australia, 14 April 2010. Canberra: Australian Institute of Health and Welfare; 2010.

12 Murray RB, Wronski I. When the tide goes out: health workforce in rural, remote and Indigenous communities. Med J Aust 2006; 185: 37-8.

13 Rural Australia Medical Undergraduate Scholarship (RAMUS) Scheme. Department of Health and Ageing; 2010. Available at http://nrha.rural health.org.au/scholarships/?IntCatId=7 [verified 7 September 2010].

14 Medical Rural Bonded Scholarship (MRBS) Scheme - Summary of scholarship information. Canberra, ACT: Department of Health and Ageing; 2011. Available at http://www.health.gov.au/internet/main/pub lishing.nsf/content/work-st-mrb-summ [verified 5 September 2011].

15 Bonded Medical Places (BMP) Scheme. Canberra, ACT: Department of Health and Ageing; 2011. Available at http://www.health.gov.au/ bmpscheme [verified 5 September 2011].
16 Evaluation of the University Departments of Rural Health Program and the Rural Clinical Schools Program. Canberra, ACT: Department of Health and Ageing; 2008.

17 Ranmuthugala G, Humphreys J, Solarsh B, Wakerman J, Dunbar JA, Solarsh G. Identifying the aspects of rural exposure that influence medical students to take up rural practice. Med Educ 2007; 41: 718-9. doi:10.1111/j.1365-2923.2007.02792.x

18 Jones M, Humphreys J, Prideaux D. Predicting medical students' intentions to take up rural practice after graduation. Med Educ 2009; 43: 1001-9. doi:10.1111/j.1365-2923.2009.03506.x

19 Worley P, Martin A, Prideaux D, Woodman R, Worley E, Lowe M. Vocational career paths of graduate entry medical students at Flinders University: a comparison of rural, remote and tertiary tracks. Med J Aust 2008; 188: 177-8.

20 Veitch C, Underhill A, Hays RB. The career aspirations and location intentions of James Cook University's first cohort of medical students: a longitudinal study at course entry and graduation. Rural Remote Health 2006; 6: 537.

21 Wilkinson D, Beilby JJ, Thompson DJ, Laven GA, Chamberlain NJ, Laurence COM. Associations between rural background and where South Australian general practitioners work. Med J Aust 2000; 173: $137-40$.

22 Worley P, Prideaux D, Strasser R, Magarey A, March R. Empirical evidence for symbiotic medical education: a comparative analysis of community and tertiary-based programs. Med Educ 2006; 40: 109-16. doi:10.1111/j.1365-2929.2005.02366.x

23 Waters B, Hughes FK, Wilkinson D. Comparative academic performance of medical students in rural and urban clinical settings. Med Educ 2006; 40: 117-20. doi:10.1111/j.1365-2929.2005.02363.x

24 Worley P, Esterman A, Prideaux D. Cohort study of examination performance of undergraduate medical students learning in community settings. BMJ 2004; 328: 207-9. doi:10.1136/bmj.328.7433.207

25 Pink B, Allbon P. The health and welfare of Australia's Aboriginal and Torres Strait Islander Peoples. Canberra, ACT: Australian Bureau of Statistics; 2008.

26 Lawson KA, Armstrong RM, Van der Weydon MB. Training indigenous doctors for Australia: Shooting the goal. Med J Aust 2007; 186: $547-50$

27 Journeys into Medicine. Canberra, ACT: Australian Indigenous Doctors' Association; 2009. Available at http://www.aida.org.au/viewpublications.aspx?id=4 [verified 5 September 2011].

28 Phillips G. CDAMS Indigenous Health Curriculum Framework, August 2004. Sydney: The Project Steering Committee, Committee of Deans of Australian Medical Schools; 2004. Available at http://www.medical deans.org.au/wp-content/uploads/CDAMS-Indigenous-Health-Curricu lum-Framework.pdf [verified 5 September 2011].

29 Medical Deans of Australia and New Zealand and The Australian Indigenous Doctors' Association: Collaboration Agreement 20082011, 2008. Available at http://www.medicaldeans.org.au/wp-content/ uploads/AIDA-Collaboration-Agreement-Signed.pdf [verified 5 September 2011].

30 Assessment and Accreditation of Medical Schools. Standards and Procedures 2009. Canberra, ACT: Australian Medical Council Limited; 2009.

31 National Clinical Training Review: Extension Report, June 2008. Sydney: Medical Deans of Australia and New Zealand; 2008.

32 Medical internship shortage at crisis point - AMA. Australian Medical Association; 2010 Available at http://ama.com.au/node/5996 [verified 5 September 2011].

33 Employment and Workforce Relations (2008). Review of Undergraduate Medical education in Australia. Australian Government Department of Education; 2008. Available at www.deewr.gov.au/HigherEducation/ Publications/HEReports/Pages/ReviewUGradMedEduAus.aspx [verified 14 January 2011]. 
34 Australian Medical Association. Australian Medical Students' Association, Medical Deans of Australia and New Zealand, Confederation of Postgraduate Medical Education Councils September 2010. Joint Statement: Action on Medical Training. Available at www.medicaldeans.org. au/action-on-medical-training-joint-statement.html [verified 14 January $2011]$.

35 The General Practice Workforce in Australia: Supply and Requirements to 2013. Sydney: Australian Medical Workforce Advisory Committee; 2005. AMWAC Report 2005.2.
36 Mullan F, Chen C, Petterson S, Kolsky G, Spagnola M. The social mission of medical education: ranking the schools. Ann Intern Med 2010; 152: 804-11.

37 Medical Schools' Outcomes Database. Medical Deans of Australia and New Zealand; 2010. Available at http://www.medicaldeans.org.au/med ical-schools-outcomes-database [verified 17 January 2011].

38 Report on the Audit of Health Workforce in Rural and Regional Australia, April 2008. Canberra, ACT: Department of Health and Ageing; 2008. 